\title{
Use of Dendrimers during the Synthesis of Pt-Ru Electrocatalysts for PEM Fuel Cells: Effects on the Physical and Electrochemical Properties
}

\author{
J. C. Calderón, ${ }^{1}$ L. Calvillo, ${ }^{2}$ M. J. Lázaro, ${ }^{2}$ and E. Pastor ${ }^{1}$ \\ ${ }^{1}$ Deparamento de Química-Física, Facultad de Química, Universidad de La Laguna, Avenida Astrofísico Francisco Sánchez s/n, \\ 38071 La Laguna (Tenerife), Spain \\ ${ }^{2}$ Instituto de Carboquímica (CSIC), Miguel Luesma Castán 4, 50018 Zaragoza, Spain
}

Correspondence should be addressed to E. Pastor, epastor@ull.es

Received 3 May 2011; Accepted 28 July 2011

Academic Editor: Maria E. Martins

Copyright ( 2011 J. C. Calderón et al. This is an open access article distributed under the Creative Commons Attribution License, which permits unrestricted use, distribution, and reproduction in any medium, provided the original work is properly cited.

\begin{abstract}
In this work, Pt-Ru catalysts were synthesized by a novel methodology which includes the use as encapsulating molecules of dendrimers of different generation: zero $(\mathrm{DN}-0)$, one (DN-1), two (DN-2), and three (DN-3). Synthesized catalysts were heattreated at $350^{\circ} \mathrm{C}$, and the effects of this treatment was established from the physical (X-ray dispersive energy (XDE) and X-ray diffraction (XRD)) and electrochemical characterization (cyclic voltammetry and chronoamperometry). Results showed that the heat-treatment benefits the catalytic properties of synthesized materials in terms of CO and methanol electrochemical oxidation. The curves for CO stripping were more defined for heat-treated catalysts, and methanol oxidation current densities were higher for these materials. These changes are principally explained from the removal of organic residues remaining on the surface of the $\mathrm{Pt}-\mathrm{Ru}$ nanoparticles after the synthesis procedure. After the activation of the catalysts by heating at $350^{\circ} \mathrm{C}$, the real importance of the use of these encapsulating molecules and the effect of the generation of the dendrimer become visible. From these results, it can be concluded that synthesized catalysts are good catalytic anodes for direct methanol fuel cells (DMFCs).
\end{abstract}

\section{Introduction}

Direct methanol fuel cells (DMFCs) are a promising power source for automotive and portable power applications. This versatility is related to ease in fuel handling, simple system design, high efficiency, and low emissions $[1,2]$. Nevertheless, the use of DMFCs is limited by the reaction kinetics for methanol electro-oxidation on platinum, which possesses a slow rate and involves steps like methanol adsorption with their respective dissociation, water adsorption also with its activation, and $\mathrm{CO}$ oxidation as intermediate of this reaction [3]. In fact, the presence of $\mathrm{CO}$ and $\mathrm{HCOO}^{-}$intermediates is determinant in slow reaction kinetics due to the strong adsorption of these species on $\mathrm{Pt}$, blocking the electroactive sites. As an alternative for solving this problem, Pt-Ru alloys have been suggested $[4,5]$ because of their higher activity for methanol electro-oxidation, stability, and ability of $\mathrm{Ru}$ for providing $\mathrm{OH}_{\mathrm{ads}}$ species, which are able to weaken and accelerate CO adsorption and oxidation [3].
These reasons motivate the implementation of novel $\mathrm{Pt}-\mathrm{Ru}$ nanoparticles synthesis procedures, with controlled metal loading, $\mathrm{Pt}: \mathrm{Ru}$ atomic proportions, particle size, and homogeneous dispersion on a determined support. Typical wet impregnation and incipient wetness methods do not allow controlling these properties [6]. An alternative is the use of dendrimers, which are three-dimensional and treelike functional macromolecules, where branches are the specific sites for nucleation process of metal precursors [7]. Branches conform the so-called generations of a dendrimer; the first-generation dendrimer is constituted by a determined number of monomers linked to a central core. Subsequent union between other monomers and the extreme of the first linked monomers generates a second generation and thus, next generations are formed until steric hindrance inhibits formation of further shells [7]. Because of these structural characteristics, they were successfully used as a template for metal nanoparticles formation, providing five principal advantages [8]: (1) the possibility of obtaining well-defined 
size and shape nanoparticles due to their uniform structure [9], (2) avoid agglomeration of nanoparticles by stabilization into the dendrimer structure [10], (3) protection towards passivation and enabling to catalytic activity by means of steric hindrance which surround the nanoparticles [11], (4) the selectivity towards access of small substrates to the encapsulated catalytic nanoparticles, controlled by the dendrimer branches, and (5) terminal amino groups of the molecule could be modified for controlling the solubility of dendrimer-nanoparticle composite, providing the possibility of linkage to others polymers [12].

Synthesis of DENs (dendrimer encapsulated nanoparticles) is widely reported in the literature [13-19], and this process usually initiates with the formation of intradendrimer metal clusters, then chemically reduced with excess of $\mathrm{NaBH}_{4}$. Changes in solution colour and UV-visible absorbance bands are the evidences for this cluster formation [20] even giving some clue about their size [21, 22]. In the case of dendrimers with noncomplexing functional groups, such as hydroxyl groups, nanoparticle formation is carried out into the dendrimer [23, 24]. However, dendrimer template formation of nanoparticles can be realized also in the external branches $[23,25]$, as is the case of amineterminated poly(amidoamine) dendrimers, which could promote the formation of nanoparticles surrounded by complexation of metal ions with dendrimeric surface amine groups [26]. The control of the $\mathrm{pH}$ of the dendrimeric solution could prevent the formation of metal complexes on the dendrimer periphery, by protonation of the surface primary amine groups, which also be available to nucleate metallic nanoparticles [27].

In this work, Pt-Ru catalysts supported on carbon nanofibers were synthesized, by reduction with sodium borohydride, making use of amino-terminal dendrimers, with zero, one, two, and three generation. Heat treatment at $350^{\circ} \mathrm{C}$ was used in order to remove the encapsulating dendrimers. Physical characterization was carried out by means of EDX, $\mathrm{XRD}$, and TEM, while electrochemical activity towards CO and methanol electrochemical oxidation was studied by cyclic voltammetry and chronoamperometry, comparing the effect of heat treatment in terms of metal loading, $\mathrm{Pt}: \mathrm{Ru}$ proportion, particle size, and catalytic activity.

\section{Experimental}

2.1. Synthesis of Catalysts. Carbon nanofibers synthesized by catalytic thermal decomposition of methane were used as carbon support. For their synthesis, an $\mathrm{Ni}: \mathrm{Cu}: \mathrm{Al}$ catalyst with a weight proportion $78: 6: 16$ was employed. After the activation of this catalyst growth of CNFs was carried out passing a methane flux at $700^{\circ} \mathrm{C}$ for $10 \mathrm{~h}$ on the catalysts. Obtained carbon nanofibers were treated with an $\mathrm{HNO}_{3}$ $\mathrm{H}_{2} \mathrm{SO}_{4} 1: 1(\mathrm{v} / \mathrm{v})$ mixture for $0.5 \mathrm{~h}$ at room temperature. For the synthesis of catalysts, different generation PAMAM dendrimers (20\% wt in methanol, Aldrich) were dissolved in ultrapure water adding the appropriate volume to achieve a $2.0 \mu \mathrm{M}$ concentration. Solutions were vigorous magnetic stirred during $30 \mathrm{~min}$, and then, metal precursors solution $\left(\mathrm{H}_{2} \mathrm{PtCl}_{6}, 8 \%\right.$ wt solution, Aldrich; and $\mathrm{RuCl}_{3}$ 99.999\%,
Aldrich) was slowly added to the dendrimer one, maintaining the agitation during the addition and after for 3 days. Then, $20 \mathrm{~mL}$ of reducing agent solution $\left(\mathrm{NaBH}_{4}, 26.4 \mathrm{mM}\right.$ in $\mathrm{NaOH} 7.0 \mathrm{M}$ ) were slowly added generating a dark colour because of the formation of Pt-Ru nanoparticles. After $24 \mathrm{~h}$ on the magnetic stirrer, carbon nanofibers was added to the reaction mixture in the presence of ultrasound agitation. The reaction mixture was maintained under stirring for 2 days, and after being filtered, it was washed with ultrapure water and dried at $60^{\circ} \mathrm{C}$ during $2 \mathrm{~h}$. Nomenclature used for these catalysts is PtRu/CNF-DN-X, being X the generation of the dendrimer used during the synthesis. Finally, catalysts were heat treated at $350^{\circ} \mathrm{C}$ in a furnace for $30 \mathrm{~min}$. In this case, the nomenclature was PtRu/CNF-DN-X TT, with X meaning as before.

2.2. EDX, XRD, and TEM Characterization. Determination of metal content and $\mathrm{Pt}-\mathrm{Ru}$ atomic ratios for the synthesized materials were made by energy dispersive X-ray (EDX) analysis, using a scanning electron microscope (LEO Mod. 440 ) at $20 \mathrm{keV}$, with a Si detector and a Be window. Xray diffraction (XRD) patterns were made by means of an universal diffractometer Panalytical X'Pert, operating with $\mathrm{Cu}-\mathrm{K}_{\alpha}$ radiation, generated at $40 \mathrm{kV}$ and $30 \mathrm{~mA}$. Scan rate was $3^{\circ} \mathrm{min}^{-1}$ with $2 \theta$ values between 10 and $100^{\circ}$. Scherrer's equation was used to calculate the metal crystallite size from $\mathrm{XRD}$, using the dimensions of (220) peak around $2 \theta=70^{\circ}$.

2.3. Electrochemical Characterization. Electrochemical activity of $\mathrm{Pt}-\mathrm{Ru}$ catalysts towards $\mathrm{CO}$ and methanol was evaluated by cyclic voltammetry and chronoamperometry. It was compared to that of the commercial $\mathrm{PtRu} / \mathrm{C}$ catalyst from E-TEK. An electrochemical thermostatized cell was used with a glassy carbon disk as working electrode, a glassy carbon bar as counter electrode and a reversible hydrogen electrode (RHE), placed inside a Luggin capillary as reference electrode. All potentials in the text are referred to the RHE electrode. A catalyst ink was prepared by mixing $2 \mathrm{mg}$ of the catalyst, $15 \mu \mathrm{L}$ of Nafion ( $5 \mathrm{wt} . \%$, Aldrich), and $500 \mu \mathrm{L}$ of ultrapure water. An aliquot of this dispersion was deposited onto the glassy carbon disk. $0.5 \mathrm{M} \mathrm{H}_{2} \mathrm{SO}_{4}$ (95-97\%, Merck) and $2.0 \mathrm{M}$ methanol (98\%, Merck) solutions were used in these experiments. CO reactivity on the different catalysts was evaluated by bubbling it into the electrochemical cell, during 10 minutes, producing an adsorbed $\mathrm{CO}$ monolayer on the deposited catalyst. Then, nitrogen $\left(\right.$ MicroGeN ${ }_{2}$, GasLab) was bubbled during 10 minutes to remove CO from the solution. Finally, cyclic voltammetric and chronoamperometric curves were recorded using an Electrochemistry Instrument $\mu$ AUTOLAB III modular equipment.

\section{Results and Discussion}

3.1. Physical Characterization of the Catalysts. EDX analysis was used for determining the metal content and Pt:Ru atomic ratio, and the results are given in Table 1 . All catalysts present similar metal content and $\mathrm{Pt}: \mathrm{Ru}$ atomic ratio, aprox. $20 \%$ wt. and $1: 1$, respectively. These values were comparable 
TABle 1: Composition and crystallite sizes for Pt-Ru catalysts.

\begin{tabular}{lccc}
\hline Catalyst & $\begin{array}{c}\text { Pt-Ru } \\
\text { (EDX) }\end{array}$ & $\begin{array}{c}\text { Metal loading } \\
\text { (\% wt.) }\end{array}$ & $\begin{array}{c}\text { Crystallite size } \\
\text { (nm) }\end{array}$ \\
\hline PtRu/CNF-DN-0 & $58-42$ & 12 & 3.3 \\
PtRu/CNF-DN-0 TT & $49-51$ & 18 & 4.1 \\
PtRu/CNF-DN-1 & $59-41$ & 20 & 3.8 \\
PtRu/CNF-DN-1 TT & $52-48$ & 17 & 3.6 \\
PtRu/CNF-DN-2 & $44-56$ & 20 & 3.0 \\
PtRu/CNF-DN-2 TT & $40-60$ & 19 & 3.8 \\
PtRu/CNF-DN-3 & $47-53$ & 19 & 3.0 \\
PtRu/CNF-DN-3 TT & $41-59$ & 21 & 2.9 \\
PtRu/C E-TEK & $45-55$ & 20 & 4.4 \\
\hline
\end{tabular}

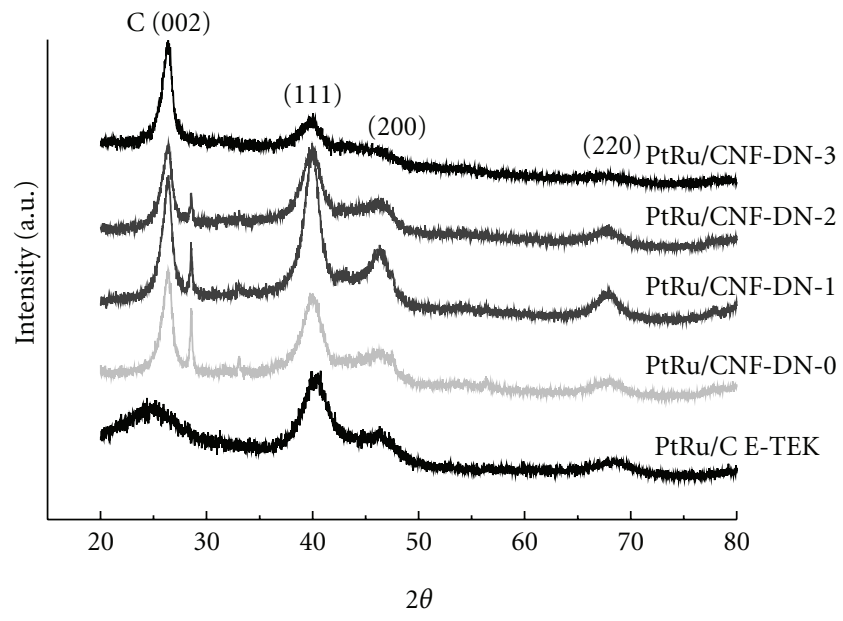

FIGURE 1: XRD diffractograms for the untreated Pt-Ru catalysts.

to those of the commercial Pt-Ru/C E-TEK catalyst and close to the nominal ones. After the heat treatment, metal loading and compositions remain similar assuming the experimental error, with the exception of the metal loading in the $\mathrm{DN}$ 0 material which increases from 12 to $18 \%$. This result can be explained by an important lose of organics during the heat treatment, which seems to be much important with this dendrimer. Concerning the $\mathrm{Pt}: \mathrm{Ru}$ atomic proportion, although the changes are small, a trend to increase the $\mathrm{Ru}$ content after heating is apparent for all catalysts, suggesting that the treatment can induce modifications in the catalysts nature, as an increase in the oxidation state of ruthenium forming ruthenium oxides [28] and, therefore, promoting changes in the original composition.

$\mathrm{XRD}$ patterns of the nonheat treated and heat-treated catalysts (Figures 1 and 2, resp.) display the characteristic peaks, (111), (200), and (220), of the face centred cubic (fcc) structure of Pt and also a diffraction peak around $24.5^{\circ}$ for $\mathrm{Pt}-\mathrm{Ru} / \mathrm{C}$ E-TEK and $26.5^{\circ}$ for PtRu/CNF. This peak corresponds to the (002) reflection of graphite basal planes and is attributed to the catalyst support. It is remarkable the appearance of new peaks at 35 and $552 \theta$ degrees in the heat-treated catalysts (Figure 2), indicating the formation of ruthenium oxides [29] and the graphitization of carbon

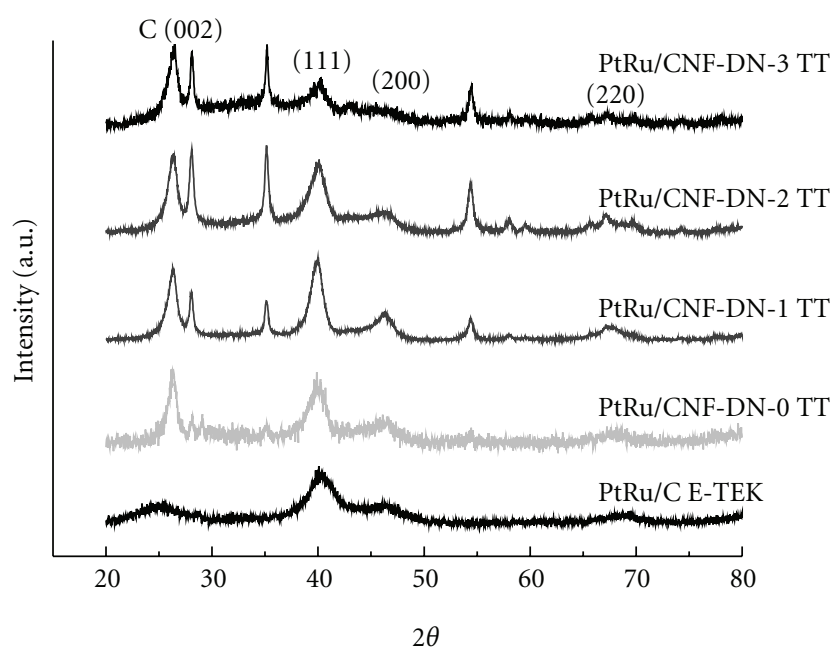

FIGURE 2: XRD diffractograms for the synthesized Pt-Ru catalysts submitted to heat treatment at $350^{\circ} \mathrm{C}$.

support with the corresponding (004) face present at the hexagonal graphite structure [30], respectively. Moreover, metal average crystallite sizes were determined with the (220) reflection peak dimensions (Table 1). Debye-Scherrer equation was used for calculating the average crystallite size of catalysts, obtaining values between 2.9 and $4.1 \mathrm{~nm}$, being PtRu/CNF-DN-3 TT the catalysts with the smallest crystallite size $(2.9 \mathrm{~nm})$. All values were smaller than that for the commercial catalyst, and the largest size was obtained for the PtRu/CNF-DN-0 TT material $(4.4 \mathrm{~nm})$. The latter result can be attributed to the low encapsulating effect of the zero generation dendrimer, considering that low generation dendrimers have an open and flat structure, losing their capacity to confine the nanoparticles [31]. This fact is verified with the small crystallite sizes obtained for synthesized catalysts using two and three generation dendrimers.

3.2. Electrochemical Characterization. Reactivity towards CO (Figures 3-5) and methanol (Figure 6) was evaluated by means of cyclic voltammetry, both for the commercial catalyst PtRu/C E-TEK and the synthesized catalysts. Current density values were normalized by the Pt loading of each electrode. CO stripping curves for heat-treated materials (Figure 5) develop a narrower oxidation peaks with a welldefined peak potential compared with the untreated catalysts (Figure 4), as well as its current densities were more similar than those of the untreated catalysts. Possibly, in the presence of dendrimers from the synthesis procedure at the surface of $n$, the untreated materials diminishes the reactivity towards $\mathrm{CO}$ because of a passivating effect on catalytic sites. According to this assumption, the CVs for the catalysts in the base electrolyte change drastically after heating, as can be seen in Figures 4 and 5, as a consequence of the elimination of the organic residues. Results in Figure 5 are in agreement with that reported in the literature for wellcleaned Pt-Ru alloys used as catalysts for CO electrochemical oxidation [32]. Then, it is proved that the treatment at $350^{\circ} \mathrm{C}$ produces $\mathrm{PtRu}$ nanoparticles activation, with appropriate 


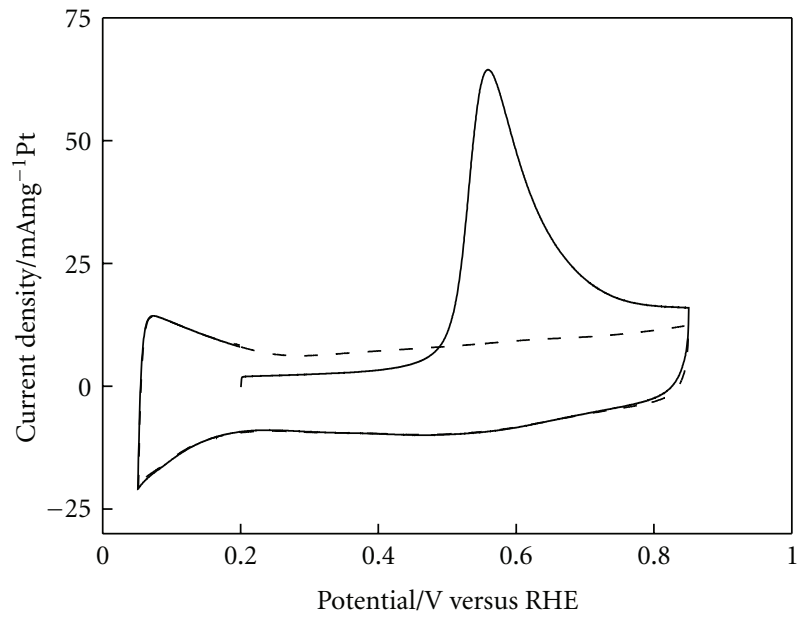

Figure 3: Cyclic voltammograms for CO oxidation at room temperature on commercial catalysts PtRu/C E-TEK. Full line: first scan. Dashed line: second scan. Scan rate: $20 \mathrm{mVs}^{-1}$. Supporting electrolyte: $0.5 \mathrm{M} \mathrm{H}_{2} \mathrm{SO}_{4}$. $\mathrm{CO}$ adsorption potential: $0.2 \mathrm{~V}$ versus RHE.

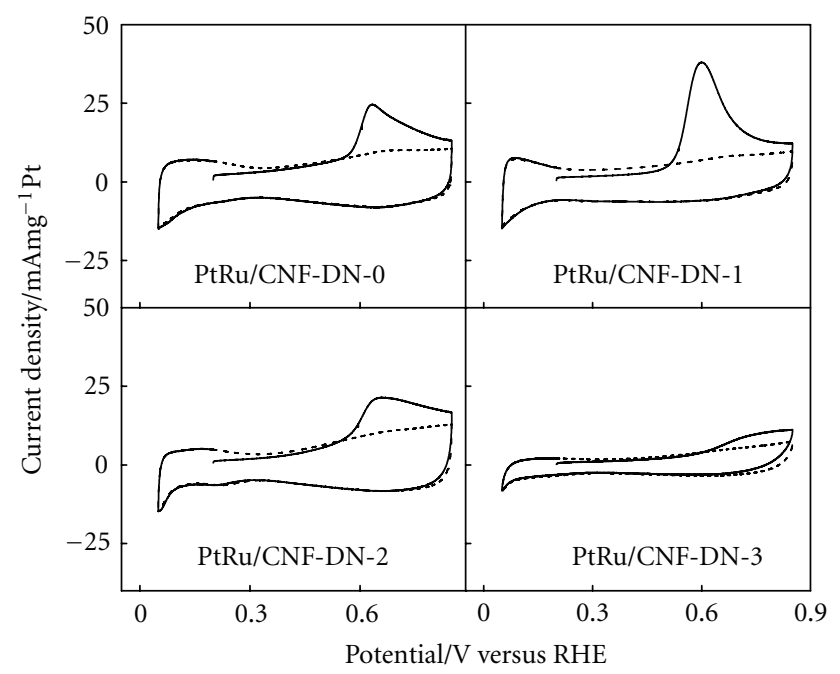

Figure 4: Cyclic voltammograms for $\mathrm{CO}$ oxidation at room temperature on untreated synthesized catalysts. Full line: first scan. Dashed line: second scan. Scan rate: $20 \mathrm{mVs}^{-1}$. Supporting electrolyte: $0.5 \mathrm{M} \mathrm{H}_{2} \mathrm{SO}_{4}$. $\mathrm{CO}$ adsorption potential: $0.2 \mathrm{~V}$ versus RHE.

surface activity towards $\mathrm{CO}$ electrooxidation, even better than the commercial PtRu/C E-TEK (which shows a broader curve shifted to more positive potentials, Figure 3 ).

Methanol electrochemical oxidation (Figure 6) presents significant differences between the untreated catalysts and those heat-treated catalysts. For the former (Figure 6(a)), commercial catalyst PtRu/C E-TEK shows a great activity with respect to the synthesized catalyst. Possibly, dendrimers kept in the material, passivating metal nanoparticles and inhibiting their catalytic activity towards methanol. However, the effect of dendrimer generation is clearly observed: the higher the generation of the dendrimer, lower

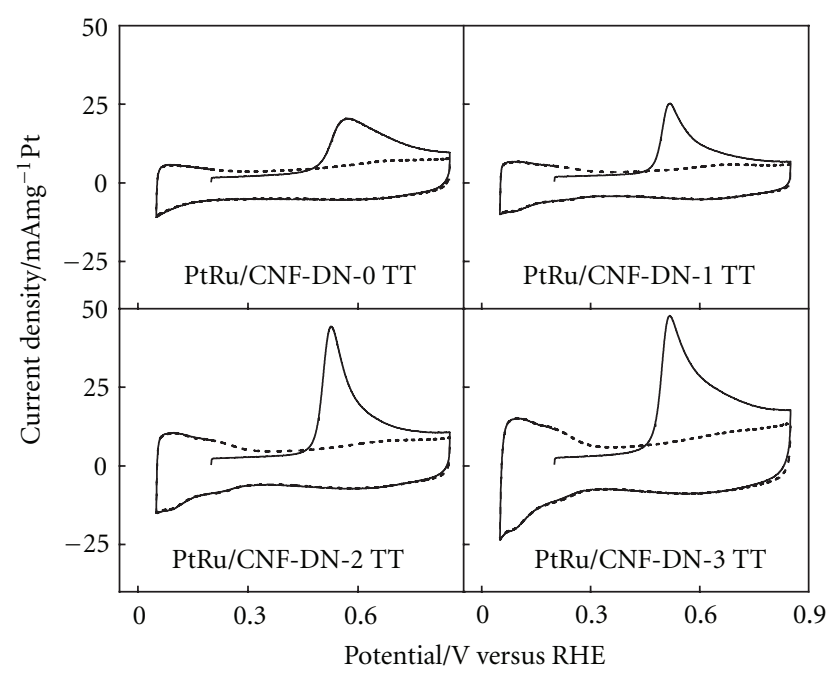

Figure 5: Cyclic voltammograms for $\mathrm{CO}$ oxidation at room temperature on the heat-treated synthesized catalysts. Full line: first scan. Dashed line: second scan. Scan rate: $20 \mathrm{mVs}^{-1}$. Supporting electrolyte: $0.5 \mathrm{M} \mathrm{H}_{2} \mathrm{SO}_{4}$. $\mathrm{CO}$ adsorption potential: $0.2 \mathrm{~V}$ versus RHE.

the the methanol oxidation current densities recorded. The explanation is conducted through the dendrimer size: $\mathrm{PtRu} / \mathrm{CNF}-\mathrm{DN}-0$ displays the better performance probably because of the relatively small size of zero generation dendrimer molecules, which did not produce a strong surface passivation. Opposite, DN-3 is the biggest molecule and, consequently, generates the highest passivation effect.

Nevertheless, heat treatment strongly promotes the methanol electrochemical oxidation on those materials prepared with dendrimers corresponding to generation higher than zero (Figure 6(b)). In this case, the catalyst synthesized in the presence of DN-0 (PtRu/CNF-DN-0 TT) shows the lowest current densities, and the activities increase with the generation of the dendrimer: PtRu/CNF-DN-3 TT displays the highest methanol oxidation current densities, followed by PtRu/CNF-DN-2 TT, PtRu/C E-TEK, PtRu/CNF-DN-1 TT, and finally, PtRu/CNF-DN-0 TT. According to Table 1, the main difference between the PtRu/CNF-DN-3 TT and the other catalysts is the small particle size, and therefore, it seems to be the main parameter conditioning the current densities attained. This fact leads us to conclude the role played by dendrimer generation. Thus, it seems that the size of dendrimer is a crucial factor for obtaining adequate crystallite sizes. However, an effect associated to changes in the distribution of the crystallographic planes in the nanoparticle induced by the dimension of the dendrimer cannot be discarded.

In order to establish the steady state performance of catalysts for methanol electrooxidation, chronoamperometry was carried out. Figure 7 displays the potentiostatic current density curves as a function of time for the heat-treated $\mathrm{Pt}-\mathrm{Ru}$ materials at $0.55 \mathrm{~V}$, as a typical working potential in DMFCs. Current density values are in the same range obtained in Figure 6(b). The same trend established from the 


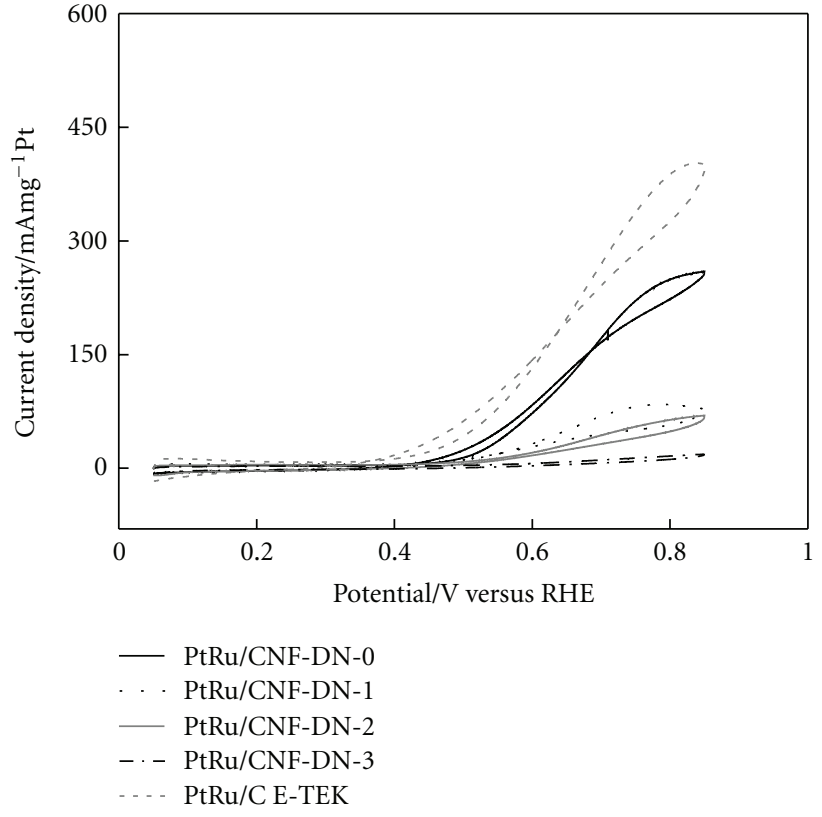

(a)

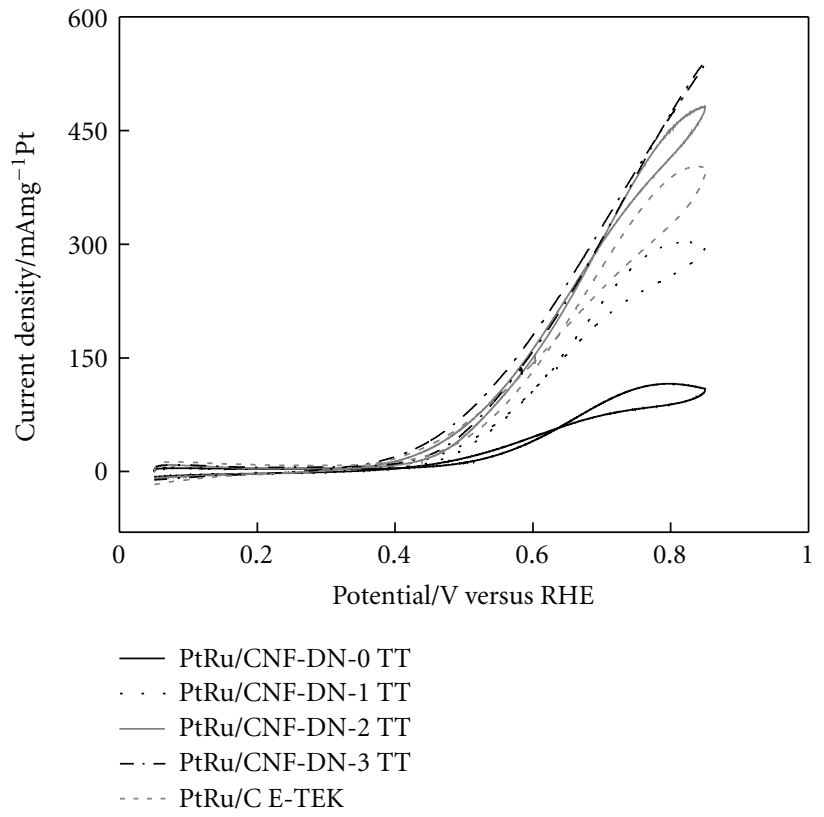

(b)

FIGURE 6: Cyclic voltammograms for methanol oxidation at room temperature on Pt-Ru synthesized catalysts. (a) Untreated catalysts (b) Heat-treated catalysts. Scan rate: $20 \mathrm{mVs}^{-1}$. Supporting electrolyte: $0.5 \mathrm{M} \mathrm{H}_{2} \mathrm{SO}_{4}$. Methanol concentration: $2.0 \mathrm{M}$.
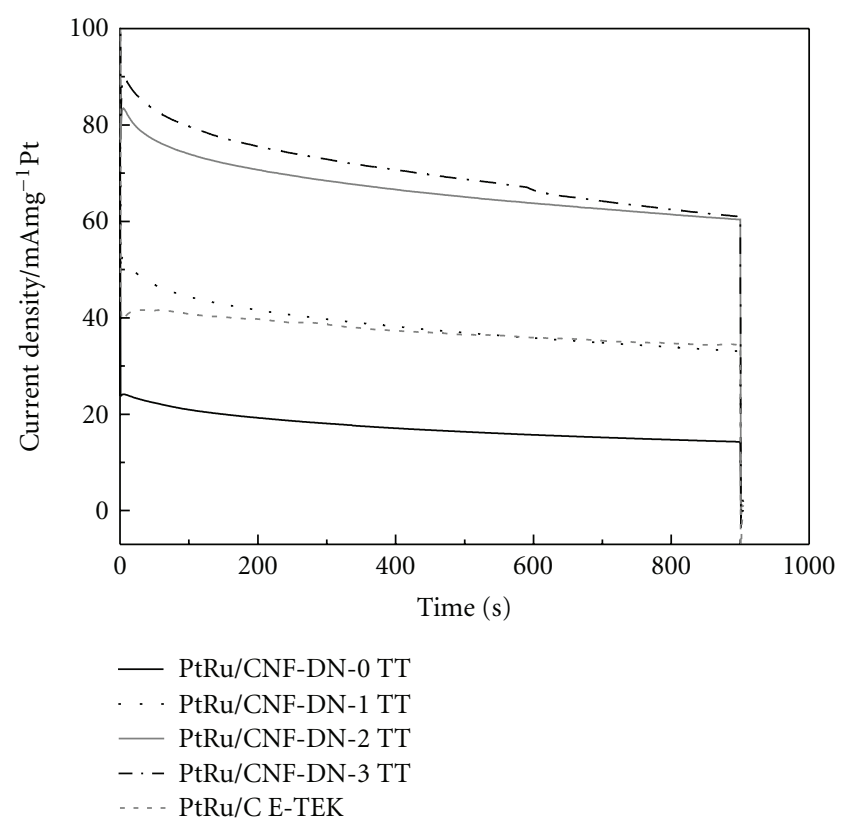

Figure 7: Current density versus time curves at room temperature for methanol oxidation on Pt-Ru synthesized catalysts. Supporing electrolyte: $0.5 \mathrm{M} \mathrm{H}_{2} \mathrm{SO}_{4}$. Methanol concentration: $2.0 \mathrm{M}$. Applied potentials: $0.55 \mathrm{~V}$.

CVs is also observed in Figure 7: again, PtRu/CNF-DN-3 TT and PtRu/CNF-DN-2 TT show the highest stationary current densities after $900 \mathrm{~s}$ at room temperature, whereas the lowest current densities correspond to PtRu/CNF-DN-0 TT.
These results confirm that dendrimer synthesis of Pt-Ru nanoparticles with an appropriate heat treatment allows to prepare catalysts with better performance than commercial ones.

\section{Conclusions}

Pt-Ru catalysts supported on carbon nanofibers have been synthesized using dendrimers of zero, one, two, and three generation. All prepared materials displayed a $\mathrm{Pt}: \mathrm{Ru}$ ratio of $1: 1$ and metal loading close to $20 \%$. These properties were near to those determined for the commercial catalyst PtRu/C E-TEK used for comparison. Crystallite size varies between 2.9 and $4.1 \mathrm{~nm}$ for the prepared materials $(4.4 \mathrm{~nm}$ for the commercial one).

A heat treatment at $350^{\circ} \mathrm{C}$ was performed with all synthesized catalysts trying to activate the nanoparticles surface. Success of heat treatment was observed in the electrochemical experiments. Thus, CO stripping curves display well-defined peaks for heat-treated catalysts, whereas untreated materials describe broader curves with less-defined CO oxidation peak potentials. Moreover, the activity of PtRu/CNF-DN-3 TT and PtRu/CNF-DN-2 TT towards methanol electrooxidation was drastically increased after the procedure, as demonstrated in both cyclic voltammetric and chronoamperometric experiments. In fact, better performance than commercial PtRu/C E-TEK was obtained for these activated materials. Then, it is concluded that dendrimer synthesis followed by temperature activation can be used for the preparation of highly active anodes for direct methanol fuel cells. 


\section{Acknowledgments}

This work was carried out with the help of Project MICINN (no. MAT2008-06631-C03-01 y-02) of the Spanish Ministry of Science and Technology. Juan Carlos Calderón is indebted to the $\mathrm{Al} \beta$ an Program for the predoctoral fellowship no. E07D403742CO.

\section{References}

[1] H. Liu, C. Song, L. Zhang, J. Zhang, H. Wang, and D. P. Wilkinson, "A review of anode catalysis in the direct methanol fuel cell," Journal of Power Sources, vol. 155, no. 2, pp. 95-110, 2006.

[2] A. H. C. Sirk, J. M. Hill, S. K. Y. Kung, and V. I. Birss, "Effect of redox state of PtRu electrocatalysts on methanol oxidation activity," Journal of Physical Chemistry B, vol. 108, no. 2, pp. 689-695, 2004.

[3] M. Watanabe and S. Motoo, "Electrocatalysis by ad-atoms part II. Enhancement of the oxidation of methanol on platinum by ruthenium ad-atoms," Journal of Electroanalytical Chemistry, vol. 60, no. 3, pp. 267-273, 1975.

[4] H. A. Gasteiger, N. Marković, P. N. Ross Jr., and E. J. Cairns, "Methanol electrooxidation on well-characterized platinumruthenium bulk alloys," Journal of Physical Chemistry, vol. 97, no. 46, pp. 12020-12029, 1993.

[5] P. K. Shen and A. C. C. Tseung, "Anodic oxidation of methanol on Pt/WO3 in acidic media," Journal of the Electrochemical Society, vol. 141, no. 11, pp. 3082-3089, 1994.

[6] Y. Gu, G. Wu, X. F. Hu et al., "PAMAM-stabilized Pt$\mathrm{Ru}$ nanoparticles for methanol electro-oxidation," Journal of Power Sources, vol. 195, no. 2, pp. 425-434, 2010.

[7] J. M. J. Fréchet, "Functional polymers and dendrimers: reactivity, molecular architecture, and interfacial energy," Science, vol. 263, no. 5154, pp. 1710-1714, 1994.

[8] R. M. Crooks, M. Zhao, L. Sun, V. Chechik, and L. K. Yeung, "Dendrimer-encapsulated metal nanoparticles: synthesis, characterization, and applications to catalysis," Accounts of Chemical Research, vol. 34, no. 3, pp. 181-190, 2001.

[9] M. Zhao, L. Sun, and R. M. Crooks, "Preparation of $\mathrm{Cu}$ nanoclusters within dendrimer templates," Journal of the American Chemical Society, vol. 120, pp. 4877-4878, 1998.

[10] M. Zhao and R. M. Crooks, "Homogeneous hydrogenation catalysis with monodisperse, dendrimer- encapsulated Pd and Pt nanoparticles," Angewandte Chemie - International Edition, vol. 38, no. 3, pp. 364-366, 1999.

[11] V. Chechik, M. Zhao, and R. M. Crooks, "Self-assembled inverted micelles prepared from a dendrimer template: phase transfer of encapsulated guests," Journal of the American Chemical Society, vol. 121, no. 20, pp. 4910-4911, 1999.

[12] H. Tokuhisa, M. Zhao, L. A. Baker et al., "Preparation and characterization of dendrimer monolayers and dendrimeralkanethiol mixed monolayers adsorbed to gold," Journal of the American Chemical Society, vol. 120, no. 18, pp. 4492-4501, 1998.

[13] H. Lang, R. A. May, B. L. Iversen, and B. D. Chandler, "Dendrimer-encapsulated nanoparticle precursors to supported platinum catalysts," Journal of the American Chemical Society, vol. 125, no. 48, pp. 14832-14836, 2003.

[14] H. Lang, R. A. May, B. L. Iversen, and B. D. Chandler, in Catalysis of Organic Reactions, pp. 243-250, Taylor \& Francis Group/CRC Press, Boca Raton, Fla, USA, 2005.
[15] A. Singh and B. D. Chandler, "Low-temperature activation conditions for PAMAM dendrimer templated Pt nanoparticles," Langmuir, vol. 21, no. 23, pp. 10776-10782, 2005.

[16] L. W. Beakley, S. E. Yost, R. Cheng, and B. D. Chandler, "Nanocomposite catalysts: dendrimer encapsulated nanoparticles immobilized in sol-gel silica," Applied Catalysis A, vol. 292, no. 1-2, pp. 124-129, 2005.

[17] H. Lang, S. Maldonado, K. J. Stevenson, and B. D. Chandler, "Synthesis and characterization of dendrimer templated supported bimetallic Pt-Au nanoparticles," Journal of the American Chemical Society, vol. 126, no. 40, pp. 12949-12956, 2004.

[18] H. Wu, Z. Liu, X. Wang, B. Zhao, J. Zhang, and C. Li, "Preparation of hollow capsule-stabilized gold nanoparticles through the encapsulation of the dendrimer," Journal of Colloid and Interface Science, vol. 302, no. 1, pp. 142-148, 2006.

[19] F. N. Crespilho, F. Huguenin, V. Zucolotto, P. Olivi, F. C. Nart, and O. N. Oliveira Jr., "Dendrimers as nanoreactors to produce platinum nanoparticles embedded in layer-bylayer films for methanol-tolerant cathodes," Electrochemistry Communications, vol. 8, no. 2, pp. 348-352, 2006.

[20] U. Kreibig and M. Vollmer, Optical Properties of Metal Clusters, Springer, Berlin, Germany, 1995.

[21] A. C. Curtis, D. G. Duff, P. P. Edwards et al., "A morphology-selective copper organosol," Angewandte Chemie-International Edition, vol. 27, pp. 1530-1533, 1988.

[22] I. Lisiecki and M. P. Pileni, "Synthesis of copper metallic clusters using reverse micelles as microreactors," Journal of the American Chemical Society, vol. 115, no. 10, pp. 3887-3896, 1993.

[23] Y. M. Chung and H. K. Rhee, "Synthesis and catalytic applications of dendrimer-templated bimetallic nanoparticles," Catalysis Surveys from Asia, vol. 8, no. 3, pp. 211-223, 2004.

[24] R. W. J. Scott, A. K. Datye, and R. M. Crooks, "Bimetallic palladium-platinum dendrimer-encapsulated catalysts," Journal of the American Chemical Society, vol. 125, no. 13, pp. 3708-3709, 2003.

[25] W. Zhang, L. Li, Y. Du, X. Wang, and P. Yang, "Gold/platinum bimetallic core/shell nanoparticles stabilized by a Fréchettype dendrimer: preparation and catalytic hydrogenations of phenylaldehydes and nitrobenzenes," Catalysis Letters, vol. 127, no. 3-4, pp. 429-436, 2009.

[26] Y. Niu, L. Sun, and R. M. Crooks, "Determination of the intrinsic proton binding constants for poly(amidoamine) dendrimers via potentiometric $\mathrm{pH}$ titration," Macromolecules, vol. 36, no. 15, pp. 5725-5731, 2003.

[27] H. Ye, R. W. J. Scott, and R. M. Crooks, "Synthesis, characterization, and surface immobilization of platinum and palladium nanoparticles encapsulated within amine-terminated poly(amidoamine) dendrimers," Langmuir, vol. 20, no. 7, pp. 2915-2920, 2004.

[28] X. Li, J. Liu, Q. Huang, W. Vogel, D. L. Akins, and H. Yang, "Effect of heat treatment on stability of gold particle modified carbon supported Pt-Ru anode catalysts for a direct methanol fuel cell," Electrochimica Acta, vol. 56, no. 1, pp. 278-284, 2010.

[29] E. S. Steigerwalt, G. A. Deluga, D. E. Cliffel, and C. M. Lukehart, "A Pt-Ru/graphitic carbon nanofiber nanocomposite exhibiting high relative performance as a direct-methanol fuel cell anode catalyst," Journal of Physical Chemistry B, vol. 105, no. 34, pp. 8097-8101, 2001.

[30] K. T. Jeng, C. C. Chien, N. Y. Hsu et al., "Performance of direct methanol fuel cell using carbon nanotube-supported Pt-Ru anode catalyst with controlled composition," Journal of Power Sources, vol. 160, no. 1, pp. 97-104, 2006. 
[31] L. Jin, S. P. Yang, Q. W. Tian, H. X. Wu, and Y. J. Cai, "Preparation and characterization of copper metal nanoparticles using dendrimers as protectively colloids," Materials Chemistry and Physics, vol. 112, no. 3, pp. 977-983, 2008.

[32] H. A. Gasteiger, N. Marković, P. N. Ross Jr., and E. J. Cairns, "CO electrooxidation on well-characterized Pt-Ru alloys," Journal of Physical Chemistry, vol. 98, no. 2, pp. 617-625, 1994. 




International Journal of

Medicinal Chemistry

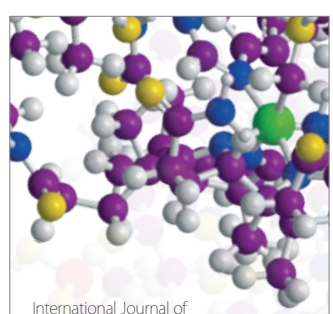

Carbohydrate Chemistry

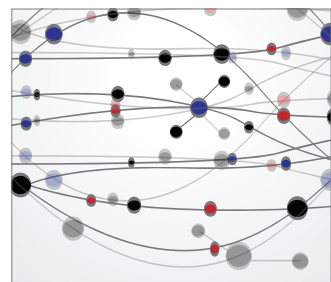

The Scientific World Journal
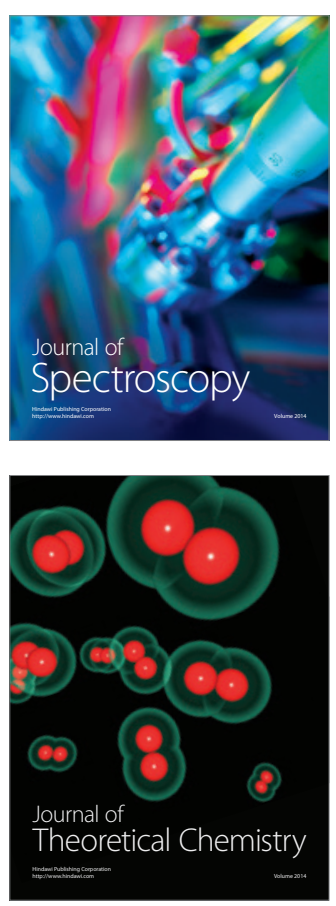
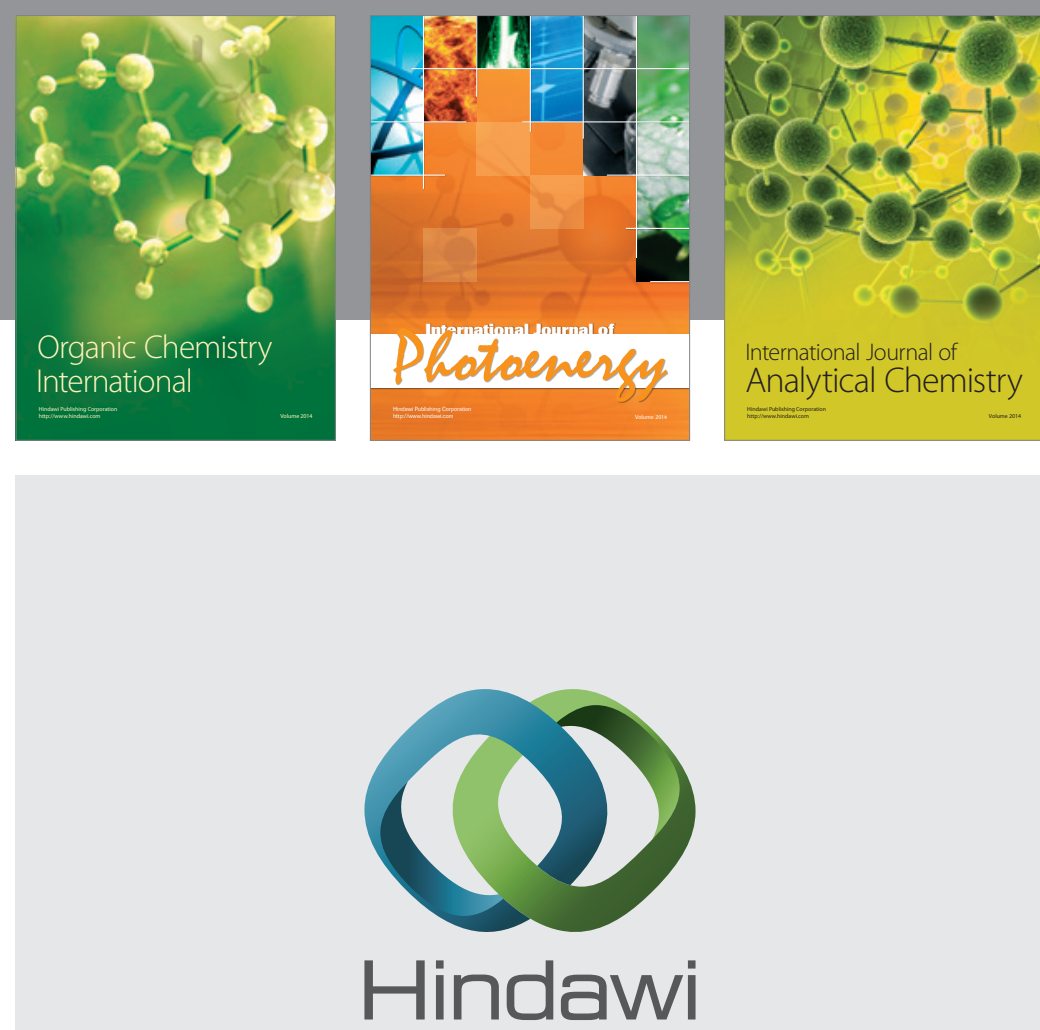

Submit your manuscripts at

http://www.hindawi.com
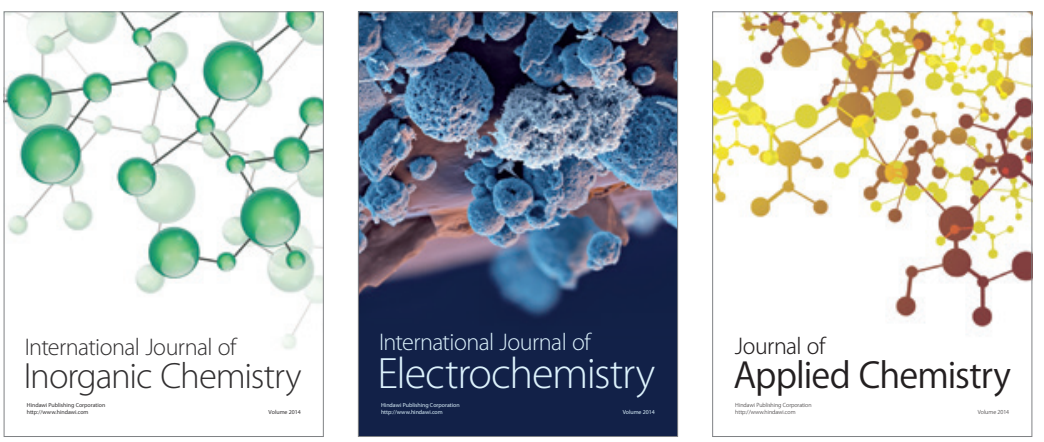

Journal of

Applied Chemistry
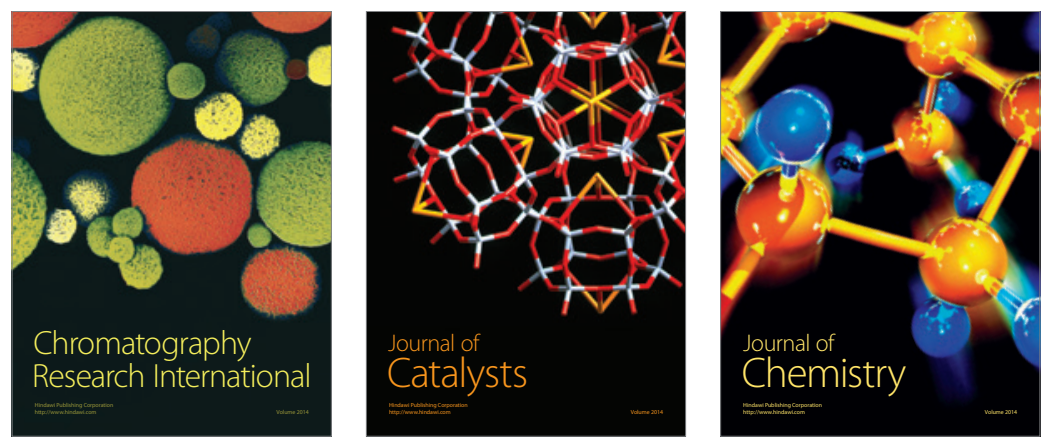
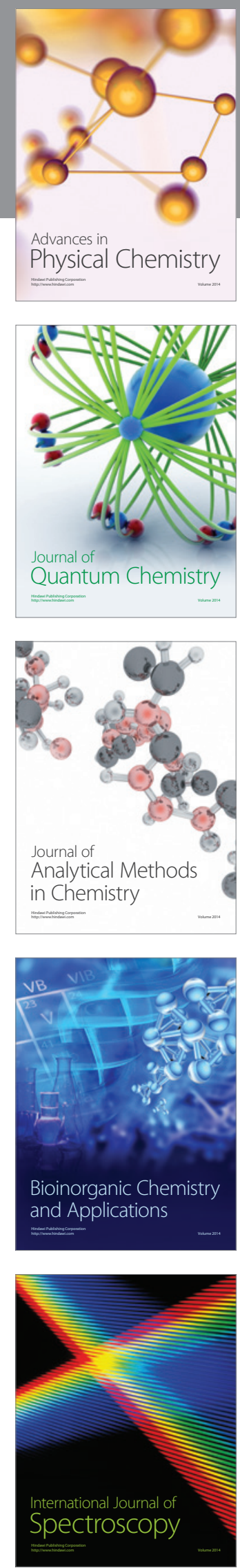